\title{
Frequency and associated factors with failure to perform the puerperal consultation in a cohort study
}

Cristiane de Souza Gonçalves 1

https://orcid.org/0000-0002-9668-5459

Juraci Almeida Cesar 2

https://orcid.org/0000-0003-0864-0486

Luana Patrícia Marmitt 3

https://orcid.org/0000-0003-0526-7954

Carla Vitola Gonçalves 4

https://orcid.org/0000-0001-6580-6417

1-4 Programa de Pós-graduação em Ciências da Saúde. Faculdade de Medicina. Universidade Federal do Rio Grande. Rio Rua Visconde de Paranaguá, 102. Rio Grande, RS, Brasil. CEP: 96.200-190. E-mail: crisdesg@gmail.com

\begin{abstract}
Objectives: to identify the frequency and factors associated with the non-realization of puerperal consultations in women resident of a medium-sized municipality in Brazil.

Methods: a prospective cohort study based on data collected in two time points, the first $48 \mathrm{~h}$ and after the $42^{\text {nd }}$ day post-childbirth. In order to analyze data, proportions were compared using the chi-square test, and the adjusted analysis was performed using Poisson regression, according to a predetermined hierarchical model. Significance level was set at $5 \%$.

Results: of the 572 women included in the study, 24.8\% did not perform puerperal consultations. The factors associated with the non-realization of puerperal consultations were: lower income (1st tercile $P R=2.01 ; C I 95 \%=1.21-3.33-2^{\text {nd }}$ tercile $P R=1.94 ; C I 95 \%=1.17$ $3.20)$ and schooling $(\leq 8$ years $P R=2.00 ; C I 95 \%=1.24-3.24)$, comorbidities during pregnancy $(P R=1.45 ; C 195 \%=1.01-2.09)$, realization of antenatal care in the public service $(P R=1.74 ; C I 95 \%=1.18-2.58)$ and non-use of contraceptive methods $(P R=3.10$; $C I 95 \%=1.86-5.16)$

Conclusions: puerperal revision does not seem to be valued in the antenatal care, mainly in the public health system. An important inequality was identified in the provision of this service, since women more prone to recurring pregnancy and with lower income and schooling were the ones that least returned to the puerperal consultation.
\end{abstract}

Key words Postpartum period, Prevalence, Health status disparities, Primary health care

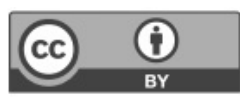




\section{Introduction}

The puerperium, or postpartum, is the period that starts immediately after birth and lasts on average six weeks, being its end chronologically unpredictable due to the anatomo-physiological changes that occur in the woman's body. 1,2

Puerperal consultation is a service ensured by Brazilian public health policies, and shall be done until the 42nd day of postpartum. ${ }^{2}$ Numerous approaches are planned to promote the health of both mother and newborn during the puerperal period, such as support to breast-feeding, family planning, detection of maternal anemia, and puerperal depression, besides the monitoring of growth and development of the newborn.2-4 The absence of maternal contact with the health services during the pregnancy-puerperal cycle represents a lost opportunity for the realization of interventions that exert a positive impact in both maternal and child health.5-7 In this way, the return of woman and newborn child to the health service must be incentivized since the prenatal care. 1,4

Even though the public policies implemented in Brazil in the last decades have increased access and coverage of the maternal-child health, the nonperformance of the puerperal consultation is still showing proportions that vary from $60.8 \%$, according to the National Demography and Health Survey of 2006 , to $80.8 \%$. Meanwhile, data from the SisPreNatal software showed that in a municipality in the Brazilian Southeast only $19.2 \%$ of the women had six or more prenatal consultations + puerperal consultation + all basic exams + anti-HIV test + immunization against tetanus. 8,9 Another study realized in southern Brazil with 3,497 women showed that the prevalence of non-return in the postpartum was of $23 \% .5$ Women with lower schooling, 5,10 with black skin color, 5 with low income, 5,10 that attended to the prenatal care in the public healthcare, that performed vaginal delivery, 5 or that reside in the rural area ${ }^{11}$ are the ones with greater risk of not returning to the puerperal health service.

The low occurrence of puerperal revision, besides being associated with a higher maternal and child morbi-mortality, 7 increases the chances of giving up breast-feeding and the non-use of contraceptive methods. ${ }^{5}$ In Brazil, few studies approach the puerperium, given that in the majority of the studies the care received by the pregnant women is evaluated up to the delivery. Thus, with this study, we aim to evaluate the frequency of the non-realization of puerperal consultations and its associated factors in women that reside in a medium-sized municipality in the south of Brazil.

\section{Methods}

This prospective cohort study verified the non-realization of the puerperal consultation in all women that gave birth between May and September of 2016 in the municipality of Rio Grande (Rio Grande do Sul, Brazil). All women with hearing or cognitive disabilities were excluded from the telephone interview.

Rio Grande is located in the coastal plain of the state of Rio Grande do Sul. Its population is of 197,228 inhabitants, being $51.8 \%(102,245)$ of the feminine gender, from which $61.4 \%(62,797)$ is in fertile age. According to data from IBGE (2010), the municipality has the 4th highest GDP of the state, and its human development index (HDI) is of 0.74 .

For the study on puerperal revision we performed the sample size calculation based in the prevalence of non-consultation in puerperium that was found in the literature, which is of around $25 \%, 5,11$ with variation between $20.2 \% 11$ and $65.7 \% .12$ The population size considered was of 1,132 births, with error of 4 percentage points and $95 \%$ confidence interval, with addition of $10 \%$ for possible losses and of $20 \%$ for design effect, totalizing 419 individuals. In regards of the investigation of associated factors, income was considered the variable with highest value, being necessary 567 individuals.

The first stage was performed in the Perinatal Research of 2016. Perinatal Research is a temporal series study that evaluates the assistance to pregnancy and childbirth in the municipality. Were eligible for this research all parturients with newborns weighing 500 grams or more or with 20 weeks or more of gestational age, residents of Rio Grande, and giving birth between Jan $1^{\text {st }}$ and Dec 31, 2016. The interviewers made daily visits to the two maternity hospitals of the municipality. Following the identification of the parturient, the interview was performed with a pre-codified and structured questionnaire. All interviews were made up to 48 hours after delivery. By the end of each day, the questionnaires were codified and typed by two independent typists, being the second typing performed in reverse order. Typing was made using the free software EpiData 3.1.

In a second moment, the women that were interviewed in the Perinatal Research 2016 were reached by telephone calls 42 days after delivery for the application of the questionnaire for the puerperal study. In the contact by phone, a pre-codified ques- 
tionnaire was applied if there was compliance in participating in the study. The questionnaires were coded and typed as described for the first stage.

After the conclusion of the second stage, a database was created from the data obtained in each stage. The variables from the Perinatal Research 2016 were demographic (age in the moment of delivery, self-reported skin color and marital status), socioeconomic (years of schooling, family wage and working during pregnancy), reproductive, comorbidities (anemia, depression, diabetes, urinary infection and gestational hypertension), prenatal care (if it was performed, when it started and number of consultations) and birth-associated (type of delivery, weight of the newborn and form of payment). The variables from the puerperal study, collected in the second stage, were of identification (name, address and date of delivery), realization of puerperal consultation, contraception (whether received orientation and is using or intend to use a contraceptive method) and breastfeeding.

We performed a bivariate analysis using prevalence ratio (PR) calculation, confidence interval of 95\% and Pearson's chi-square test, with a level of significance of $p<0.05$. The analysis of associated factors was performed using Poisson regression adjusted according to a hierarchical model of causality. The first level, the most distal, included the demographic and socioeconomic variables. In the second level were included the obstetric and prenatal assistance variables. In the third level, the most proximal, were included the variables associated with delivery, breastfeeding and contraception. The variables were selected using the Backward method. In this method, the variables are put in the model according to their hierarchical level and variables with $p \leq 0.20$ value are maintained.

According to Perinatal Research 2016, 1,132 births were registered in the municipality of Rio Grande from May to September of 2016. After an average of six attempts to contact the parturients via telephone, $572(50.5 \%)$ were interviewed and included in this study.

The research project was approved by the Ethics Committee in Research of the Federal University of Rio Grande (FURG) under the number 86/2016.

\section{Results}

From the 572 women included in the study, 142 (24.8\%) did not attend to puerperal consultation. On average, the parturients were 27 years old ( $\mathrm{SD} \pm$ 7.9), $71.5 \%$ had white skin and $82.6 \%$ lived with the partner in the moment of delivery. Concerning the socioeconomic data, $43.9 \%$ had nine or more years of schooling, with average income of R \$2,939.93 and $50.6 \%$ worked during pregnancy. As for the obstetric and prenatal assistance variables, $50.5 \%$ of the women were primipara and $99.3 \%$ attended to at least one prenatal consultation. The average number of consultations was of $8.6(\mathrm{SD} \pm 2.8)$, and $80.9 \%$ started prenatal care in the first trimester of pregnancy, with $53.9 \%$ of the consultations performed by Health Unic System (SUS, Portuguese acronym). Regarding the type of delivery, $60 \%$ were by Cesarean section, with average gestational age of 39 weeks $(\mathrm{SD} \pm 2.7)$. The average weight of the newborns was of $3,256.6 \mathrm{~g}$ and $73.4 \%$ of the deliveries were performed by SUS (Table 1).

Table 1 also presents the adjusted analysis, where it was evidenced that the lower the income (1 st tercile $\mathrm{PR}=2.01 \mathrm{CI} 95 \%=1.21-3.33 ; 2$ nd tercile $\mathrm{PR}=1.94 \mathrm{CI} 95 \%=1.17-3.20)$ and the schooling $(\leq 8$ years $\mathrm{PR}=2.00 \mathrm{CI} 95 \%=1.24-3.24)$, the greater the risk of non-realization of the puerperal consultation. Women that had some morbidity during pregnancy showed a risk $45 \%$ higher of not performing the puerperal consultation when compared to the healthy ones $* \mathrm{PR}=1.45 ; \mathrm{CI} 95 \%=1.01-2.09)$. As for the type of service used in the prenatal care, women that attended to consultations via SUS showed a greater chance of not attending to the puerperal consultation $(\mathrm{PR}=1.74 ; \mathrm{CI} 95 \%=1.18-2.58)$ when compared to the ones that had private follow up or used health insurance plans. Moreover, the parturients that reported to not use contraceptive methods showed a risk three times higher of not attending consultations in the postpartum $(\mathrm{PR}=3.10$; CI95\%=1.86-5.16).

\section{Discussion}

The puerperal revision is an unmatched moment to identify maternal and child risk factors. The low occurrence can be associated with a higher frequency of diseases and deaths, as well as with premature ablactation. Another important fact is that in this occasion family planning can be reinforced, thus avoiding the reoccurrence of early pregnancy. 1,5,7,13

The observed frequency of non-realization of puerperal consultation in this study was of $24.8 \%$. This rate is similar to what was found in the few studies on the subject in Brazil and in other countries. A population-based study that included 3,497 women in Pelotas, a neighboring city, showed that $23 \%$ of the population did not attended to the puerperal consultation. 5 In other countries such as Morocco, one fifth of the 1,530 studied women did 
Descriptive, crude and adjusted analysis for factors associated with the non-performance of puerperal consultation in a municipality of the extreme south of Brazil, from May to September of 2016 ( $N=572$ ).

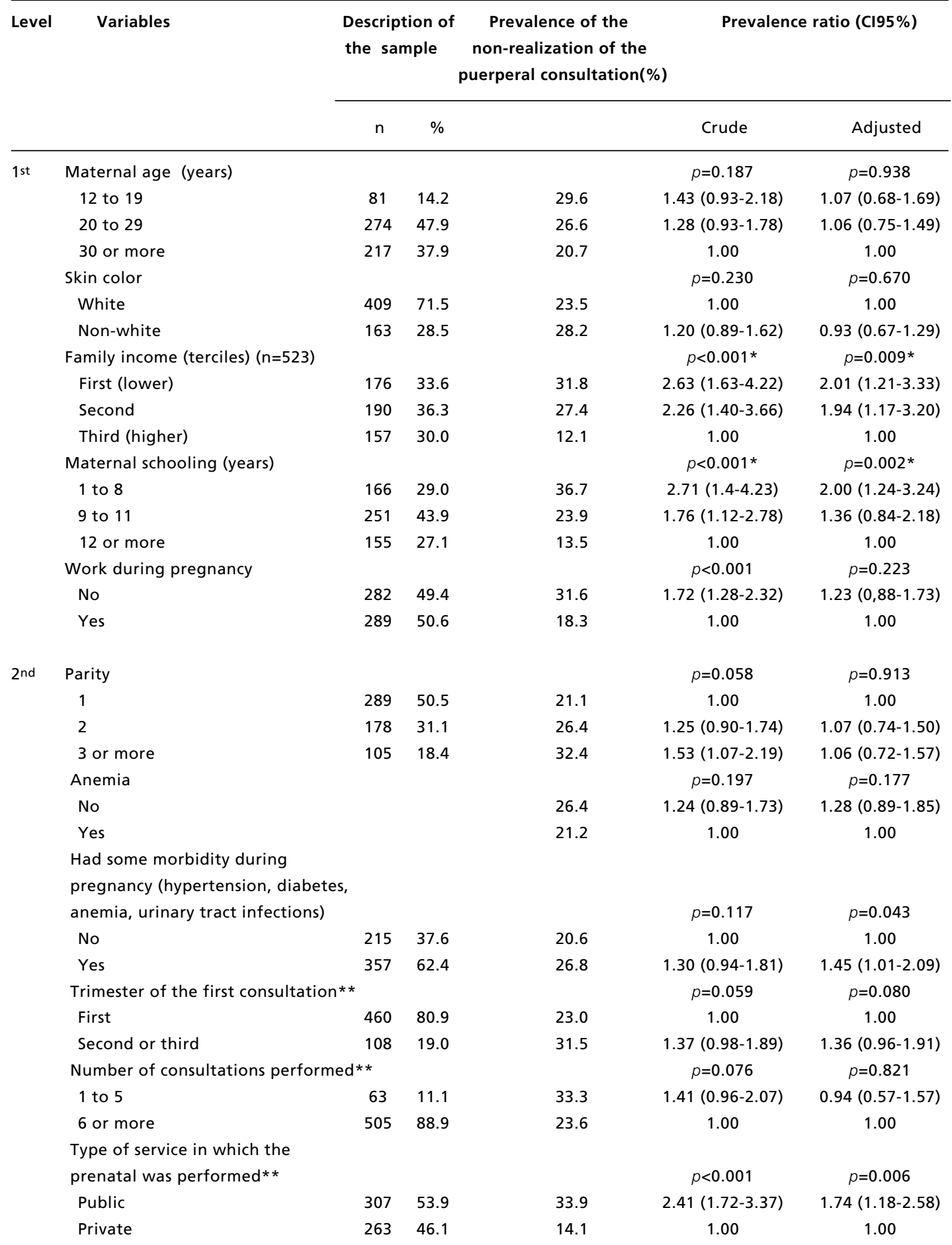

*P-value of the linear tendency test; $* *$ Information available for 568 parturients that attended to the prenatal care; 1 st, $2^{\text {nd }}$ and 3 rd hierarchic levels of the Poisson regression.

continue 
Descriptive, crude and adjusted analysis for factors associated with the non-performance of puerperal consultation in a municipality of the extreme south of Brazil, from May to September of $2016(\mathrm{~N}=572)$.

\begin{tabular}{|c|c|c|c|c|c|c|}
\hline \multirow[t]{2}{*}{ Level } & \multirow[t]{2}{*}{ Variables } & \multicolumn{2}{|c|}{$\begin{array}{l}\text { Description of } \\
\text { the sample }\end{array}$} & $\begin{array}{c}\text { Prevalence of the } \\
\text { non-realization of the } \\
\text { puerperal consultation(\%) }\end{array}$ & \multicolumn{2}{|c|}{ Prevalence ratio ( $\mathrm{Cl} 95 \%)$} \\
\hline & & $n$ & $\%$ & & Crude & Adjusted \\
\hline \multirow[t]{14}{*}{$3 \mathrm{rd}$} & Type of delivery & & & & $p=0.157$ & $p=0.570$ \\
\hline & Vaginal & 229 & 40.0 & 27.9 & $1.23(0.92-1.63)$ & $0.90(0.63-1.28)$ \\
\hline & Cesarean section & 343 & 60.0 & 22.7 & 1.00 & 1.00 \\
\hline & Financing of the delivery & & & & $p<0.001$ & $p=0.161$ \\
\hline & Public & 420 & 73.4 & 29.8 & $2.66(1.66-4.26)$ & $1.58(0.83-3.01)$ \\
\hline & Private & 152 & 26.6 & 11.2 & 1.00 & 1.00 \\
\hline & Breastfeeding & & & & $p=0.246$ & $p=0.414$ \\
\hline & No & 217 & 37.9 & 22.1 & 1.00 & 1.00 \\
\hline & Yes & 355 & 62.1 & 26.5 & $1.20(0.88-1.62)$ & $1.17(0.80-1.70)$ \\
\hline & Use of hormonal contrace & & & & & \\
\hline & method $(n=479)$ & & & & $p<0.001$ & $p<0.001$ \\
\hline & None & 11 & 2.3 & 63.6 & $2.28(1.38-3.77)$ & $3.10(1.86-5.16)$ \\
\hline & Oral contraceptive & 278 & 58.0 & 20.1 & $0.72(0.52-1.01)$ & $1.15(0.81-1.65)$ \\
\hline & Injectable contraceptive & 190 & 39.7 & 27.9 & 1.00 & 1.00 \\
\hline
\end{tabular}

*P-value of the linear tendency test; **Information available for 568 parturients that attended to the prenatal care; 1 st, 2 nd and 3 rd hierarchic levels of the Poisson regression.

not attend to the puerperal consultation, 10 while in China this proportion was of $20.2 \%$ among 347 women interviewed.11 Even though the prenatal coverage in Brazil is rising, reaching $98.7 \%, 8$ the puerperal coverage is still requiring more attention, stimulation and/or public policies that promote the importance of the postpartum revision, since women often focus too much attention in the newborn and can easily overlook their own health needs.

In the present study, we observed a linear tendency in relation to income and schooling. Women belonging to the first (lower) and to the second tercile of income had doubled chances of not performing the puerperal consultation when compared to the ones of the third tercile (higher). We also verified that the lower the schooling, the higher the risk of non-consulting in the postpartum, having the women with up to eight years of schooling twice the chances of not consulting in the puerperium when compared with the ones with 12 or more years of study. Other studies on the puerperal assistance also observed that women with lower income and with lower educational level were the ones with greater likelihood of not receiving medical attention in the postpartum.5,10 This fact is extremely concerning, given that these women are frequently the ones with more doubts and difficulties concerning breastfeeding and contraception, what exposes the newborn to an increased risk of premature ablactation and the woman to a non-planned pregnancy.

In addition to the observed inequality in income and schooling, we also verified that the women that performed the prenatal accompaniment via SUS had a risk $74 \%$ higher of not performing the puerperal consultation when compared to the ones that used the private system. We can infer that even though the public services consider the gestational care effectively concluded only after the puerperal revision, the awareness on the importance of this consultation is not being performed in the prenatal care of the Basic Health Units (Unidades Básicas de Saúde UBS). A study that used data from SisPreNatal in order to evaluate the fulfillment of the prenatal routine of 1,498 pregnant women verified that only $19.5 \%$ of them concluded all the mandatory stages of the gestational care, with more than half of the women not having puerperal assistance. ${ }^{9}$ We would like to highlight that the importance of the puerperal revision must be considered since the prenatal care, not letting this matter to be approached only in the maternity discharge. After all, this is a moment where the woman receives plenty of information concerning the health of the newborn, which are 
often prioritized in detriment of information concerning her own health.

Women that informed not to use any contraceptive methods had thrice the chances of not performing the puerperal consultation. This is a particularly alarming observation, since scientifically reputable centers such as The Office of Disease Prevention and Health Promotion (ODPHP) advises that the interpartal interval is of at least two years to ensure a reduced risk of maternal and child morbimortality. ${ }^{13}$ In Brazil, the Basic Care Manual, which approaches low-risk prenatal, advises that family planning must be discussed with women still in the prenatal, offering them different contraceptive methods, since women can already return to active sexual life in the $20^{\text {th }}$ day after delivery. ${ }^{2}$ Besides that, in this study we observed that women with lower schooling and income are in the group with the lowest puerperal revision, showing an increased risk of a new non-planned pregnancy.

The puerperal consultation is an important moment to perform interventions capable of promoting the maternal and child health. However, our findings showed that there is inequality in the occurrence of non-consultation in the puerperium, which can interfere directly in the health of the mother and child in a short or long term. We emphasize that women with lower schooling, lower income, that had prenatal care using SUS and that were not using any contraceptive methods showed a higher risk of not performing the puerperal revision. These women are in the group with the greatest social vulnerability and that can have an unwanted premature pregnancy. We believe that this situation can be improved with the usage of a better approach in the prenatal care on the importance of the puerperal consultation, and that the reinforcement on the subject becomes part of the matters present in the waiting rooms and courses for pregnant women in UBS.

Women that showed some comorbidity (urinary infection, hypertension, diabetes and anemia) during the prenatal had a decrease of $45 \%$ in the puerperal revision in comparison to women that were healthy during pregnancy. This fact is in accordance with the lack of incentive or even elucidation in the prenatal consultations about the importance of the postpartum revision. The less assisted group was precisely the more vulnerable to health grievances due to the presence of pathologies during pregnancy, being susceptible to complications and further occurrences in the long term. A study with 4,875 Indian women confirmed the importance of consultation in the postpartum, where $7.4 \%$ of women examined in the first week of the postpartum had severe anemia and $46 \%$ had moderate anemia, being risk of death detected in $7.6 \%$ of the parturients. 14

It is important to highlight that pregnant women with comorbidities had a reduced puerperal revision. It is known that pathologies should be evaluated in the postpartum, since many women can remain with chronic complications that can grow in seriousness. ${ }^{15}$ Anemia is one of the most frequent postpartum complications among the parturients, and it is many times associated with fatigue and difficulty in providing care for the newborn. 14,15 Thus, draw the attention to the high risk prenatal physicians and to the maternity hospitals of reference to this group of pregnant women, since these parturients are the ones that need more attention and understanding concerning the importance of the puerperal accompaniment.

Even though we did not collect data about the residing addresses of the participants and the presence of the Basic Unit of Family Health, we emphasize that $61 \%$ of the municipality is covered by the service. One characteristic of this region is that the central area has less coverage of the Family Health Unit (Unidade de Saúde da Família - USF), but is the area with the higher purchasing power and its residents probably make use of complementary health services. The city outskirts has the highest coverage of Family Health Strategy (Estratégia de Saúde da Familia - ESF), and is where most women with lower income and schooling reside. We thus believe that these women belong to the areas where more community health agents (CHA) can be found. A hypothesis that can be discussed is that these CHA have a more watchful approach for the prenatal coverage and childcare. A measure that can be relevant is to offer the puerperal consultation in the same occasion of the childcare consultation, simplifying the schedule.

We conclude that the puerperal revision does not seem to be valorized in the prenatal. Besides, we identified an important inequality in the provision of this service, as women with lower income and schooling, that used the public health system for the prenatal and the ones more exposed to a recurring pregnancy were the ones that less returned to the health service for the puerperal consultation.

We suggest that more attention is paid to the already available provisions in the current policies for the prenatal, delivery and puerperium, where home visit is recommended during the first week of the postpartum. This visit aims to supervise both women and child in order to guide on the appropriate care and to identify possible risk factors for the rea- 
lization of the recommendations. ${ }^{3,7}$ We also emphasize the important work of the CHAs in the identification of pregnant women in the areas of each team of family health, as well as the performance of nurses in the orientation and accompaniment of these pregnant women and parturients, aiming to promote the health of this population. Maybe the active search of these women is the only way to reduce the inequality found in this study, and, for this to happen, the CHAs and the nurses need to be attentive on the pregnant women in their area. Studies performed in other countries with women that received domiciliary visits in the puerperal period observed an increased occurrence of appropriate care and higher satisfaction of women.11,16-19 In England, where there is an universal health system with visits up to the $28^{\text {th }}$ day postpartum , the accompaniment of 2,568 women in the pregnancy-puerperal period showed positive results for socially disadvantaged groups. 19

\section{References}

1. Santos FAPS, Brito RS, Mazzo MHSN. Puerpério e revisão pós-parto-significados atribuídos pela puérpera. Rev Min Enferm. 2013; 17 (4): 859-63.

2. Brasil. Ministério da Saúde. Secretaria de Atenção à Saúde. Departamento de Atenção Básica. Cadernos de Atenção Básica, $n^{\circ} 32$. Atenção ao pré-natal de baixo risco. Brasília, DF; 2013.

3. Brasil. Ministério da Saúde. Secretaria de Atenção à Saúde. Política Nacional de Atenção Integral à Mulher: princípios e diretrizes $1^{\mathrm{a}}$ edição, $2^{\mathrm{a}}$ reimpressão, Brasília, DF. 2011. [acesso em $07 \mathrm{dez}$ 2015]. Disponível em: $<$ http://bvsms.saude.gov.br/bvs/publicacoes/politica_nacio nal_mulher_principios_diretrizes.pdf>

4. Brasil. Ministério da Saúde. Portaria $n^{\circ} 1.459$, de 24 de junho de 2011. Institui, no âmbito do Sistema Único de Saúde - SUS - a Rede Cegonha. [acesso em 07 dez 2015]. Disponível em: http://bvsms.saude.gov.br/bvs/saudelegis/gm/2011/prt1459 _24_06_2011.html>

5. Matijasevich A, Santos IS, Silveira MF, Domingues MR, Barros AJ, Marco PL, Barros F. Inequities in maternal postnatal visits among public and private patients: 2004 Pelotas cohort study. BMC Public Health. 2009; 9 (335): 1-10.

6. Batista $\mathrm{KBC}$, Lago TDG, Lavras C. Atenção à gestante e à puérpera no SUS - SP: manual técnico do pré-natal e puerpério. São Paulo: Secretaria de Saúde do Estado de São Paulo; 2010.

7. Nawal D, Goli S. Birth preparedness and its effect on place of delivery and post-natal check-ups in Nepal. PLoS One. 2013; 8 (5): e60957.

8. Brasil. Ministério da Saúde. Pesquisa Nacional de Demografia e Saúde da Criança e da Mulher - PNDS 2006: dimensões do processo reprodutivo e da saúde da criança.
Among the limitations of the study, difficulties were found in the tracking of the parturients because of changes in phone number and/or loss of contact from the part of the investigators, which could have been a source of selection bias. Even being the contact by phone a simple and almost universal method, changes in phone numbers are common, as well as the reporting of incorrect numbers or the occurrence of blocked phone lines, being this difficulties faced by other studies as well.20,21 Another limitation refers to the validation of the data collected through interviews, mainly the kind of information that relies on memory and cooperation of the informant. Finally, there is a possibility of recall bias, since some mothers may have forgotten or omitted data. However, many publications that evaluated prenatal assistance were performed with information acquired from self-reports. 22,23

Brasília, DF. 2009. [acesso em 07 dez 2015]. Disponível em:

http://bvsms.saude.gov.br/bvs/publicacoes/pnds_crianca_m ulher.pdf $>$.

9. Andreucci CB, Cecatti JG, Macchetti CE, Sousa MH. Sisprenatal as a tool for evaluating quality of prenatal care. Rev Saúde Pública. 2011; 45 (5): 1-9.

10. Assarag B, Dubourg D, Maaroufi A, Dujardin B, Brouwere V. Maternal postpartum morbidity in Marrakech: what women feel what doctors diagnose?. BMC Pregnancy Childbirth. 2013; 13 (225): 1-8.

11. Xiang Y, Xiong J, Tian M, Yuan F, Feng Z. Factors influencing the utilization of postpartum visits among rural women in China. J Huazhong Univ Sci Tech Med Sci. 2014; 34 (6): 869-74.

12. Rahman M, Haque S, Zanan S. Factors affecting the utilization of postpartum care among young mothers in Bangladesh. Health and Social Care in the Community. 2011; 19 (2): 138-47.

13. Cha S, Chapman D, Wan W, Burton CW, Masho SW. Discordance pregnant intentions in couples and rapid repeat pregnancy. Am J Obstet Gynecol. 2016; 214 (4): 494.e1e12.

14. Iyengar K, Yadav K, Sen RS. Early postpartum maternal morbidity among rural women of Rajasthan, India: a community-based study. J Health Popul Nutr. 2012; 30 (2): 213-25.

15. Brasil. Ministério da Saúde. Secretaria de Atenção à Saúde. Departamento de Ações Programáticas Estratégicas. Gestação de alto risco: manual técnico. 5 ed. Brasília, DF; 2012. [acesso em $07 \mathrm{dez}$ 2015]. Disponível em: $<$ http://bvsms.saude.gov.br/bvs/publicacoes/manual_tecnic o_gestacao_alto_risco.pdf>. 
16. Furnieles-Paterna E, Hoyuelos-Cámara H, Montiano-Ruiz I, Peñalver-Julve N, Fitera-Lamas L. Estudio comparativo y aleatorizado de la visita puerperal en el domicilio de la madre y en el centro de salud. Matronas Prof. 2011; 12 (3): 65-73.

17. Tsai PJS, Nakashima L, Yanamoto J, Ngo L, Kaneshiro B. Postpartum follow-up rates before and after the postpartum follow-up initiative at Queen Emma Clinic. Hawaii Med J. 2011; 70 (3): 56-9.

18. Olds DL, Kitzman H, Knudtson MD, Anson E, Smith JA, Cole R. Effect of home visiting by nurses on maternal and child mortality: results of a 2-decade follow-up of a randomized clinical trial. JAMA Pediatr. 2014; 168 (9): 800-6

19. Homer CS, Leap N, Edwards N, Sandall J. Midwifery continuity of care in an area of high socio-economic disadvantage in London: A retrospective analysis of Albany Midwifery Practice outcomes using routine data (1997-2009). Midwifery. 2017; 48: 1-10.
20. Domingues FB, Clausell N, Aliti GB, Dominguez DR, Rabelo ER. Educação e monitorização por telefone de pacientes com insuficiência cardíaca: ensaio clínico randomizado. Arq Bras Cardiol. 2011; 96 (3): 233-9.

21. Martins EJ, Giugliani ERJ. Quem são as mulheres que amamentam por 2 anos ou mais? J Pediatr (Rio J). 2012, 88 (1): 67-73.

22. Santos Neto ET, Leal MC, Oliveira AE, Zandonade E, Gama SGN. Concordância entre informações do cartão da gestante e da memória materna sobre assistência do prénatal. Cad Saúde Pública. 2012; 28 (2): 256-66.

23. Zanchi M, Gonçalves CV, Cesar JA, Dumith SC. Concordância entre informações do Cartão da Gestante e do recordatório materno entre puérperas de uma cidade brasileira de médio porte. Cad Saúde Pública. 2013; 29 (5): 1019-28.

Received on January 2, 2018

Final version presented on June 14, 2018

Approved on November 30, 2018 